\title{
Postharvest fruit rot caused by Pestalotiopsis sp. on grape in Korea
}

\author{
Jian Xin Deng • Hyun Kyu Sang • Yong Soo Hwang • \\ Byung Seon Lim • Seung Hun Yu
}

Received: 10 October 2012 / Accepted: 20 June 2013 / Published online: 7 July 2013

(C) Australasian Plant Pathology Society Inc. 2013

\begin{abstract}
In 2010, fruit rot disease was observed on the 'Cheongsoo' grape cultivar in a store house in Daejeon, Korea. The causal agent was determined to be a species of Pestalotiopsis not previously described in the literature. Pathogenicity tests revealed that the fungus is pathogenic to the fruit of the 'Cheongsoo' grape. This is the first report of fruit rot diseases on 'Cheongsoo' grape caused by Pestalotiopsis sp. in Korea.
\end{abstract}

Keywords 'Cheongsoo' grape $\cdot$ Pestalotiopsis $\cdot$ Morphology · Sequence analysis · Pathogenicity

Eight grape cultivars have been released in Korea since a grape breeding program started in the early 1960s. One grape cultivar, 'Cheongsoo' (1993), is an early season table grape that produces white seedless fruit with good quality and high productivity (Park et al. 2009a, b). In October 2010, severe fruit rot was observed on the 'Cheongsoo' grape during storage in Yuseong, Daejeon, Korea. Initial symptoms of fruit rot disease mostly occurred at the ruptured connection between the pedicel

J. X. Deng $\cdot$ H. K. Sang $\cdot$ S. H. Yu $(\bowtie)$

Department of Applied Biology, College of Agriculture and Life Sciences, Chungnam National University, Daejeon 305-764, Korea e-mail: shunyu@cnu.ac.kr

\section{Y. S. Hwang}

Department of Horticultural Science, College of Agriculture and Life Sciences, Chungnam National University,

Daejeon 305-764, Korea

B. S. Lim

National Institute of Horticultural and Herbal Science,

Rural Development Administration, Suwon 440-706, Korea

Present Address:

J. X. Deng

Department of Plant Protection, College of Agriculture,

Yangtze University, Jingzhou 434025, China and berry, and at wounds on the fruit (Fig. 1a). Following infection, the fruit skin turned reddish brown, after which the area of discoloured skin increased and whitish mycelium developed on the lesions. The severely infected fruits then became rotten and were separated completely from the pedicels.

Diseased fruits of the 'Cheongsoo' grape were collected from a store house in Yuseong, Daejeon, Korea. Infected grape fruits were surface sterilized with sodium hypochlorite ( $2 \%$ available chlorine) for $2 \mathrm{~min}$ and then incubated in a moist chamber at $25^{\circ} \mathrm{C}$ to isolate causal pathogens. Cultures of fungi belonging to the genus Pestalotiopsis were obtained from the areas of the fruit showing symptoms.

Colonies of the fungus grown on PDA were white and floccose cottony, forming a marked concentric ring with dense and thick mycelia $7.5-8.5 \mathrm{~cm}$ diam. in size (Fig. 2a, b). Hyphal tips of the fungus were inoculated on PDA medium. Autoclaved segments of carnation leaves (Dianthus caryophyllus) were placed on the developing colonies to promote sporulation (Fisher et al. 1982; Strobel et al. 1996). Acervuli that developed on carnation leaves were black, erumpent, pustule-like, unilocular, oval or irregular in outline and 100-200 (-250) $\mathrm{mm}$ (Fig. 2c, d). Conidiogenous cells were lageniform to ampulliform or subcylindrical, colourless, and smooth-walled (Fig. 2e). Conidia were fusiform, straight or slightly curved, five-celled, and 19.5-29.2 ×4.6-7.2 $\mu \mathrm{m}$ (mean 25.2-6.2 $\mu \mathrm{m}$, $n=50$ ) in size (Fig. 2f, g). The darker median cells were three celled (rarely two), subcylindrical to doliiform, umber to fuliginous. Normally, the upper two cells were brown to umber with a darker band at the septa between them, while the lowest cell was lighter coloured. The apical and basal cells were conical in shape and colorless. Appendages appeared at the apex and base. Apical appendages were unknobbed. There were two to four appendages, mostly three, and they were 18-40 (-43) $\mu \mathrm{m}$ long. Basal appendages were single, centric, with unknobbed tips, and 3.8-12.2 $\mu \mathrm{m}$ long. The conidial morphology of the fungus was quite different from that of Pestalotiopsis menezesiana and P. uvicola, which 
Fig. 1 Symptoms on 'Cheongsoo' grape fruit caused by Pestalotiopsis sp. in a store house (a) and during pathogenicity tests $(\mathbf{b}-\mathbf{d})$
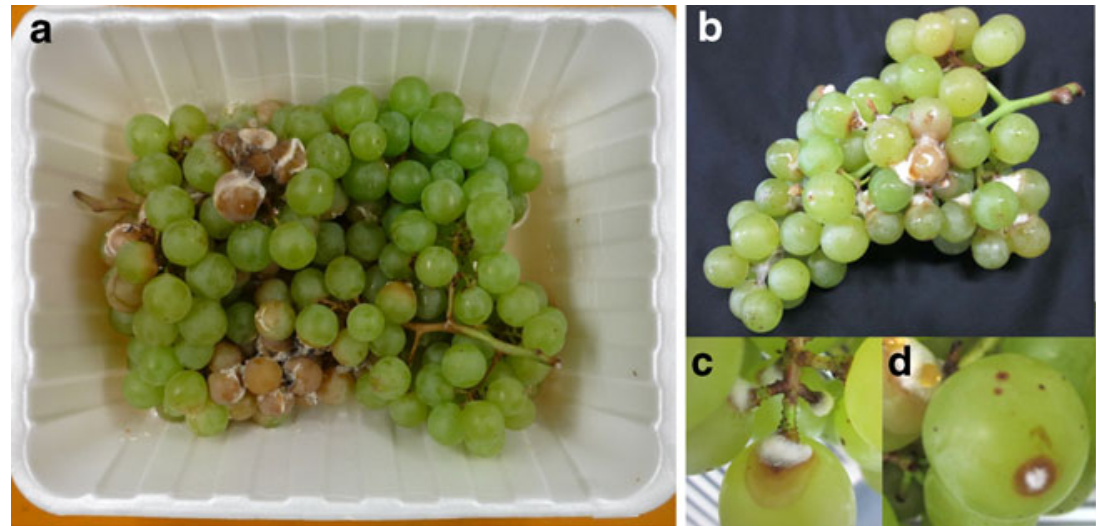

are two causal agents of fruit rot disease on grape (Xu et al. 1999, Table 1). Moreover, the morphology was very similar to that of $P$. longisetula among related species, but it could be differentiated based on its relatively longer basal appendages (Table 1). Two cultures of the fungus (CNU 100093 and 100094) were deposited in the Culture Collection of Chungnam National University (CNU) Fungal Herbarium, Daejeon, Korea and the Korean Agricultural Culture Collection (KACC), Suwon, Korea.

Genomic DNA was extracted according to the method described by Park et al. (2005). The internal transcribed spacer (ITS) region of the ribosomal DNA gene was then amplified by primers ITS5 and ITS4 (White et al. 1990), while the $\beta$ tubulin (BT2) gene was amplified by primers Bt2a and Bt2b (Glass and Donaldson 1995). The sequences of the amplified products were then deposited in the GenBank database and assigned accession numbers JQ288418 (ITS) and JQ288419 (BT2). BLAST searches revealed that the present fungus was identical to Pestalotiopsis sp. (UCD2559AR) in the BT2 gene sequence (HQ288311) and its ITS gene sequence differed by one nucleotide (HQ288234), while it differed from Pestalotiopsis longisetula by four and one nucleotides of the BT2 and ITS gene sequences, respectively. Their phylogenetic relationship (Fig. 3) was determined by RAxML analysis (Stamatakis et al. 2008). Apparently, the present fungus was closely related to Pestalotiopsis sp. 2 (UCD2559AR) isolated from Vitis vinifera associated with grapevine trunk diseases (Urbez-Torres et al. 2012). Although sequence data of the isolate (UCD2559AR) was deposited in the GenBank database (HQ288234 and HQ288311), the morphological description of the fungus was not reported. In order to give a new epithet to our fungus, morphological comparison between our fungus and Pestalotiopsis sp. 2 (UCD2559AR) is needed.

Pathogenicity tests of the fungus were conducted on two grape cultivars, 'Cheongsoo' and 'Campbell Early'. To accomplish this, conidia of the fungus identified here produced on
Fig. 2 Pestalotiopsis sp. (CNU 100093) on 'Cheongsoo' grape. a-b Colonies on PDA at $25^{\circ} \mathrm{C}$ for 7 days. c-d Acervuli on autoclaved segments of carnation leaf (scale bar $=50 \mu \mathrm{m}$ ). e Conidiogenous cells (scale bar $=20 \mu \mathrm{m}) . \mathbf{f}-\mathbf{g}$ Conidia (scale bar $=20 \mu \mathrm{m}$ )

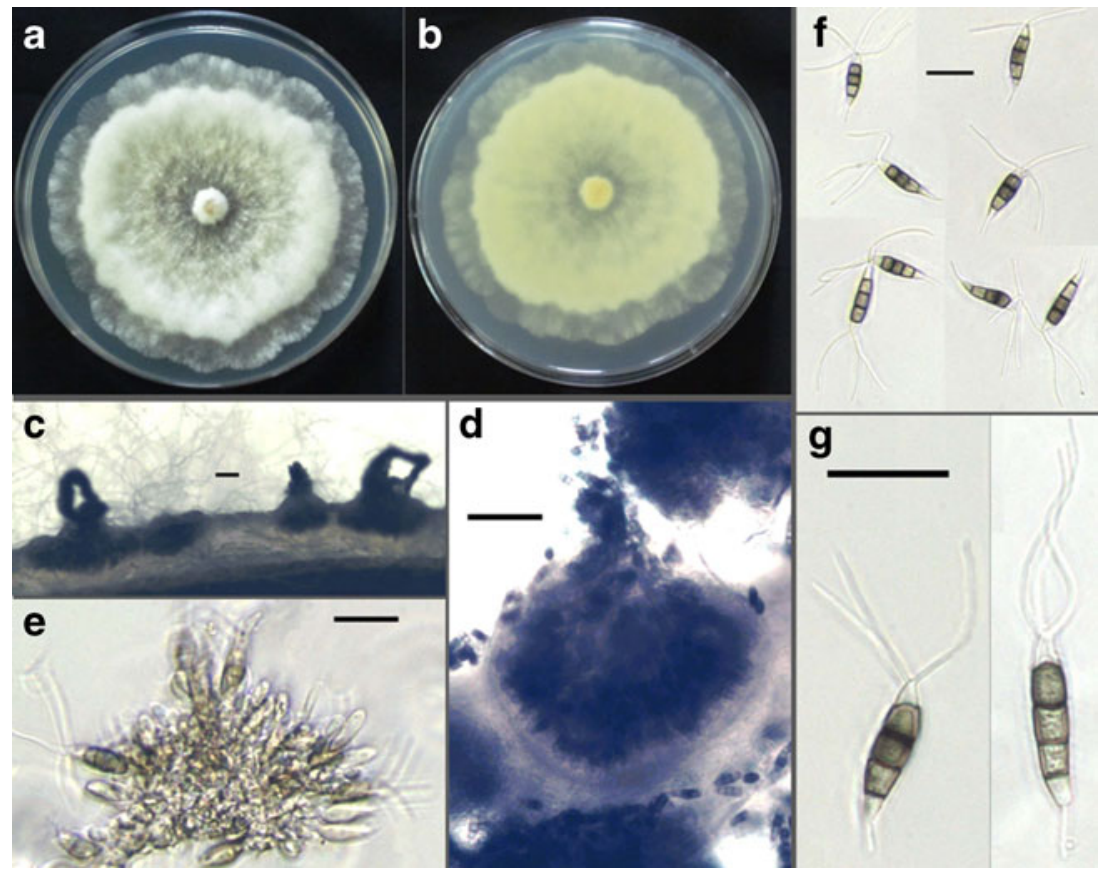


Table 1 Morphological comparison of the present fungus (Pestalotiopsis sp. CNU 100093) with related species

\begin{tabular}{|c|c|c|c|c|c|}
\hline \multirow[t]{2}{*}{ Species } & \multirow[t]{2}{*}{ Conidial size $(\mu \mathrm{m})$} & \multirow[t]{2}{*}{ Number of apical appendages } & \multicolumn{2}{|c|}{ Length $(\mu \mathrm{m})$ of appendages } & \multirow[t]{2}{*}{ Reference } \\
\hline & & & Apical & Basal & \\
\hline Present fungus & $19.5-29.2 \times 4.6-7.2$ & 2-4 (mostly 3 ) & $18-40(-43)$ & $3.8-12.2$ & In this study \\
\hline P. crassiuscula & $20-28 \times 7.5-9$ & 3 & $10-23$ & $2.5-5$ & Guba 1961 \\
\hline P. lambertiae & $18.9-24.7 \times 5.9-7.3$ & 3 & $12.4-16.9$ & $1.3-5.9$ & Liu et al. 2006 \\
\hline \multirow[t]{2}{*}{ P. longisetula } & $21-29 \times 6-7$ & 3 & $20-32$ & $3-6$ & Kasra et al. 2008 \\
\hline & $25-33 \times 6.6-8$ & $3-4$ & $22-44$ & $3.2-8(-9.5)$ & Maas 1998 \\
\hline P. photiniae & $20-24 \times 7-8$ & 3 & $16-18$ & up to 7 & Guba 1961 \\
\hline \multirow[t]{2}{*}{ P. menezesiana } & $19-26 \times 6.5-9$ & 3 & $9-31$ & 6 & Guba 1961 \\
\hline & $19-26 \times 6-8$ & 3 & $9-32$ & 6 & Xu et al. 1999 \\
\hline \multirow[t]{3}{*}{ P. uvicola } & $18-25 \times 5.5-7.5$ & $2-3$ & $13-22$ & 7 & Guba 1961 \\
\hline & $20-28 \times 6-8$ & $2-5(3-4)$ & & & Ryu et al. 1993 \\
\hline & $17-27 \times 5-6.5$ & $2-3$ & $9-26$ & 7 & Xu et al. 1999 \\
\hline
\end{tabular}

PDA media were flushed with distilled water and adjusted to $1 \times 10^{6}$ spores $/ \mathrm{ml}$. Grape clusters were then surface sterilized with sodium hypochlorite ( $2 \%$ available chlorine) for $5 \mathrm{~min}$ and rinsed three times with distilled water. The spore suspension was subsequently sprayed on sterile grape clusters, placed in moistened clean boxes and incubated for 2 weeks at $25^{\circ} \mathrm{C}$. A control was treated with distilled water. Disease symptom development was then observed every 2 days and the number

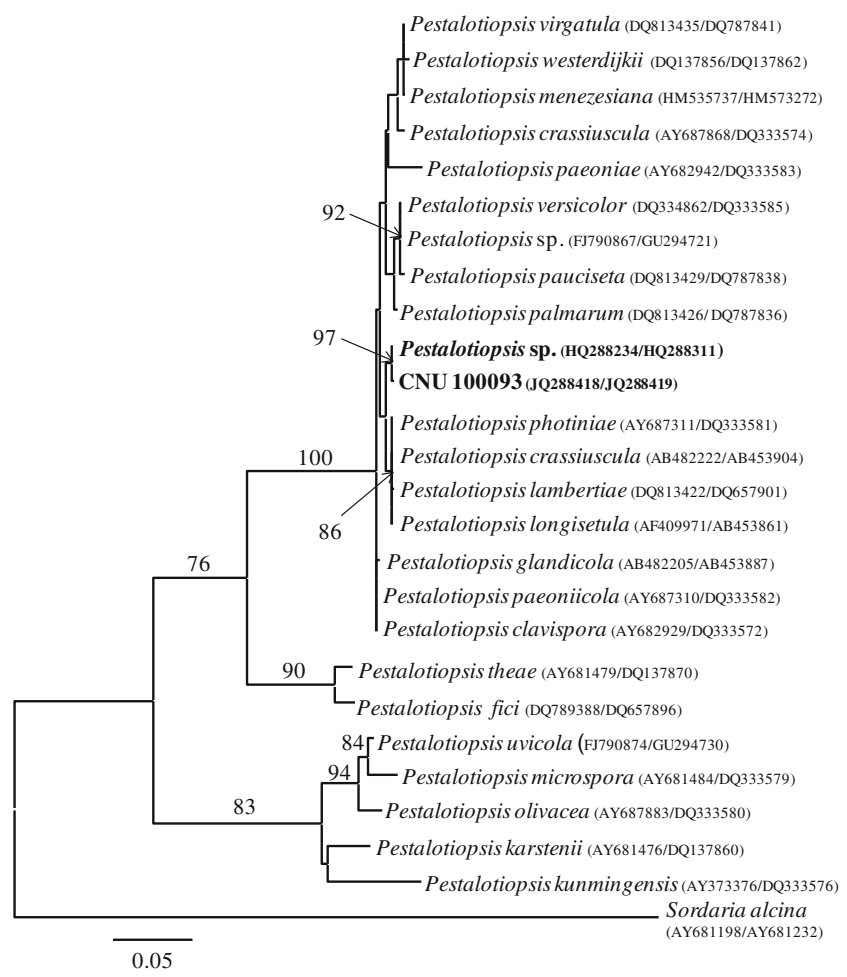

Fig. 3 Maximum likelihood tree generated from the combined data of ITS and $\beta$-tubulin gene sequences of Pestalotiopsis species. Bootstrap values $(>70 \%)$ from 1,000 replicates are shown at each node. The bar indicates the number of substitutions per position of infected grapes was counted. The severity of disease was determined by the percentage of the infected grapes. Severe infection of the 'Cheongsoo' grape was observed 14 days after artificial inoculation with the present fungus and the symptoms were similar to those of grapes with the fruit rot disease observed in store houses (Fig. 1b); however, the 'Campbell Early' grape cultivar did not show any disease symptoms. Normally, white hyphae initially appeared at the point of rupture (the area connecting pedicel and fruit berry) after 2 days. Later, pale reddish brown fruit skin was observed near the point of rupture, which enlarged with time. In addition, the grape fruits became rotten (Fig. 1c). The fungus could infect grape berries from scars of fruit skin (Fig. 1d). After 2 weeks, 30$40 \%$ of grapes in each cluster were infected, while little infection ( $0-2 \%)$ was found in the control group. Disease severity is shown in Fig. 4.

$\mathrm{Xu}$ et al. (1999) isolated several fungi such as Botrytis, Alternaria, Pestalotiopsis, Penicillium, Stemphylium and

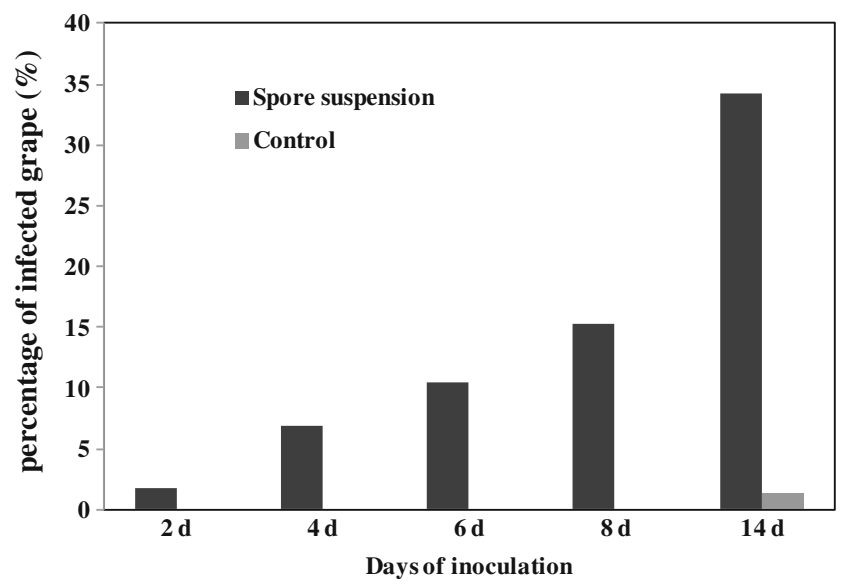

Fig. 4 Disease severity of Pestalotiopsis sp. inoculated on 'Cheongsoo' grape. The columns indicate the percentage of infected berries after 2, 4, 6,8 and 14 days 
Rhizopus from rotted berries of grapes in Japan. They also found that Pestalotiopsis menezesiana and P. uvicola initiate postharvest disease of grapes. The presence of Pestalotiopsis spp. on canes, woody tissue, berries, flowers, and leaves of grapevines has also been reported in Australia (CastilloPando et al. 2001; Sergeeva et al. 2005). Pestalotiopsis was one of the prevalent fungi isolated from the cankers of grapevines in Arkansas and Missouri (Urbez-Torres et al. 2009), and it was the second most common fungus isolated from grapevine cankers in Texas (Urbez-Torres et al. 2012). Urbez-Torres et al. (2012) reported that Pestalotiopsis sp. and P. uvicola occurred on cankers and bleached canes of grapevines, and could induce canker of grape canes. In Korea, P. uvicola has been reported to cause fruit rot disease of grape (Ryu et al. 1993), but limited information on conidial morphology of the species was described (Table 1). This is the first report of Pestalotiopsis sp. causing fruit rot disease on the grape cultivar 'Cheongsoo'.

Acknowledgments This study was supported by a grant from Regional Subgenebank Support Program of the Rural Development Administration (RDA), Republic of Korea.

\section{References}

Castillo-Pando M, Somers A, Green CD, Priest M, Sriskanthades M (2001) Fungi associated with dieback of Semillon grapevines in the Hunter Valley of New South Wales. Aust Plant Pathol 30:59-63

Fisher NL, Burgess LW, Toussoun TA, Nelson PE (1982) Carnation leaves as a substrate and for preserving cultures of Fusarium species. Phytopathology 72:151-153

Glass NL, Donaldson GC (1995) Development of primer sets designed for use with the PCR to amplify conserved genes from filamentous ascomycetes. Appl Environ Microbiol 61:1323-1330
Guba EF (1961) Monograph of Monochaetia and Pestalotia. Harvard University Press, Cambridge

Kasra S, Estahbanati JAR, Makameh (2008) A new Pestalotiopsis species for the mycoflora of Iran. Rostaniha 9:118-118

Liu AR, Wu XP, Xu T, Guo LD, Wei JG (2006) Endophytic Pestalotiopsis from Hainan, China. Mycosystema 25:389-397

Maas JL (ed) (1998) Compendium of strawberry diseases, 2nd edn. APS Press, St. Paul

Park MS, Seo GS, Bae KS, Yu SH (2005) Characterization of Trichoderma spp. associated with green mold oyster mushroom by PCR-RFLP and sequence analysis of ITS regions of rDNA. Plant Pathol J 21:229-236

Park HJ, Ko JM, An NR, Kim YS, Cha HC (2009a) Contents of transresveratrol in Korean grape cultivars, including 'Kyoho'. J Plant Biol 52:319-324

Park KS, Yun HK, Rho JH, Kim KH (2009b) Major characteristics of grape cultivars bred by a grape breeding program in Korea. Acta Hort 827:511-514

Ryu HW, Lee YH, Cho WD, Kim WG, Myung IS, Jin KS (1993) Compendium of fruit tree disease with colour plates. Agricultural Science Institute, Suwon, p 286

Sergeeva V, Priest M, Nair NG (2005) Species of Pestalotiopsis and related genera occurring on grapevines in Australia. Aust Plant Pathol 34:255-258

Stamatakis A, Hoover P, Rougemont J (2008) A rapid bootstrap algorithm for the RAxML web servers. Syst Biol 57:758-771

Strobel GA, Yang XS, Sears J, Kramer R, Sidhu RS, Hess WM (1996) Taxol from Pestalotiopsis microspora, an endophytic fungus of Taxus wallichiana. Microbiology 142:435-440

Urbez-Torres JR, Adams P, Kama J, Gubler WD (2009) Identification, incidence and pathogenicity of fungal species associated with grapevine dieback in Texas. Am J Enol Vitic 60:497-507

Urbez-Torres JR, Peduto F, Striegler RK, Urrea-Romero KE, Rupe JC, Cartwright RD, Gubler WD (2012) Characterization of fungal pathogens associated with grapevine trunk diseases in Arkansas and Missouri. Fungal Divers 52:169-189

White TJ, Bruns T, Lee S, Taylor J (1990) Amplification and direct sequencing of fungal ribosomal RNA genes for phylogenetics. In: Innis MA, Gelfand DH, Shinsky JJ, White TJ (eds) PCR protocols: a guide to methods and applications. Academic, San Diego

Xu L, Kusakari S, Hosomi A, Toyoda H, Ouchi S (1999) Postharvest diseases of grapes caused by Pestalotiopsis spp. Ann Phytopathol Soc Japan 65:305-311 